\title{
A Comparative Study and Analysis of Two Types of Bio-Oil Samples Obtained from Freshwater Algae and Microbial Treated Algae
}

Zeban Shah ${ }^{1 *}$, Renato Cataluna Veses ${ }^{1}$ and Rosangela da Silva ${ }^{2}$

${ }^{1}$ Federal University of Rio, Grande do Sul, Av. Bento Gonçalves, Porto Alegre, RS, Brazil

${ }^{2}$ Pontifical Catholic University of Rio, Grande do Sul, Av. Ipiranga, Porto Alegre, RS, Brazil

\begin{abstract}
Pyrolysis experiments of two types of algal biomass (Spirogyra) freshwater Algae (FWA) and microbial treated algae (MTA) were carried out in an electrically heated stainless steel reactor to determine the effects of pyrolysis temperature, pyrolysis product yields and bio-oil properties. After pyrolysis two types of bio-oil were produced, freshwater algae bio-oil (FWAB) and microbial treated algae bio-oil (MTAB). Gas chromatography/mass spectrometry (GC-MS) analysis and Fourier transform infrared spectroscopy (FTIR) has been done of both types of bio-oil samples and also a comparison is shown between these two samples and explained it with the help of graphs and tables. The bio-oil was obtained from pyrolysis in which temperature of the system was kept $25^{\circ} \mathrm{C}$ and then increased up to $650^{\circ} \mathrm{C}$ time by time. After pyrolysis the obtained bio-oil was introduced to distillation and then analyzed by GC-MS technique and FTIR, which show different peaks and results of different compounds and functional groups present in both bio-oil samples and a noticeable difference is shown between these two bio-oil samples on the basis of hydrocarbons as well as other compounds.
\end{abstract}

Keywords: Freshwater algae; Microbial treated algae; Pyrolysis; GCMS; FTIR

\begin{abstract}
Abbreviations: GC-MS: Gas Chromatography-Mass Spectrometer; FTIR: Fourier Transform Infrared Spectroscopy; FWAB: Bio-oil obtained from Freshwater Algal Biomass; MTAB: Bio-oil obtained from Microbial Treated Algal Biomass; FWA: Freshwater Algae; MTA: Microbial Treated Algae.
\end{abstract}

\section{Introduction}

Bio-Oil, a liquid product from thermal conversion of biomass has been paid attention to provide fuels and chemicals [1]. The rising demand for energy, chemicals, and materials from sustainable resources poses challenging efforts. A pyrolytic process converts biomass feedstock into three classes of products: a solid (or char), a liquid (also known as bio-oil from pyrolysis or simply bio-oil), and a gas [2]. Biomass has been entering into our life and industries as an interesting renewable resources used to provide second generation of Biofuels or chemicals [3]. Abundant amount and $\mathrm{CO}_{2}$ neutrality with low sulfur and nitrogen contents make biomass a sustainable and eco-friendly energy source $[4,5]$. This has been demonstrated by many researchers, the experiments on catalytic pyrolysis of biomass were generally carried out in a fixed bed reactor or fluidized bed $[6,7]$. On the other hand biodiesel has higher molecular weight, density, viscosity and pour point than conventional diesel fuel $[8,9]$. Higher molecular weight and viscosity of biodiesel causes low volatility and poor fuel atomization, injector coking, piston ring sticking and leading incomplete combustion [10] as well as it has cold flow property which is a barrier to use it in cold or chill weather [11]. anyhow the best benefit of Bio-oils is that they are preparing from renewable sources like corpse, plants, trees and residues etc. approximately 100 years ago, Rudolf Diesel tested Bio-oil as the fuel for his engine that was available with him $[12,13]$. Soybean oil was transesterified into ethyl and methyl esters, and comparisons of the performances of the fuels with diesel were made $[14,15]$. Also, methyl esters have been prepared from palm oil by transesterification using methanol in the presence of a catalyst $(\mathrm{NaOH})$ or $(\mathrm{KOH})$ in a batch reactor [16]. Ethan oils a preferred alcohol in the transesterification process compared to methanol because it is derived from natural agricultural products and is renewable and biologically less objectionable in the environment. The success of rapeseed ethyl ester production would mean that biodiesel's two main raw materials would be agriculturally produced, renewable and environmentally friendly [17]. Methyl, ethyl, 2-propyl and butyl esters were prepared from canola and linseed oils through transesterification using $\mathrm{KOH}$ and/or sodium alkoxides as catalysts. In addition, methyl and ethyl esters were prepared from rapeseed and Sunflower oil using the same catalysts $[18,19]$. Biomass is a renewable source which has received attention due to various characteristics, particularly its low cost and wide availability. Biomass can be converted into bio-fuel by means of different processes, e.g., reductive combustion, liquefaction, pyrolysis and gasification [20]. The use of biomass is particularly interesting when it involves waste products such as waste vegetable oil, fruit seeds, sugarcane bagasse, sugarcane straw, rice husks, coconut fibers, and coffee grounds, which are also potential sources of energy [21]. Taking into account that bio-oil from pyrolysis contains a very complex mixture of products, its chromatographic analyses requires the coupling of these instruments with a mass selective detector to aid the identification of eluted products [22]. The mass spectrum, sometimes, is not sufficient to identify unknown compounds, due to the similarity of their spectra, thus the use of reference compounds may be an aid to overcome this problem. Furthermore, the use of analytical standards may allow quick quantification through one of several techniques, such as the internal standard method [23,24]. However bio-oils from pyrolysis may include up to several hundred of compounds [25]. Among many kinds of alternative energies, biodiesel can be directly applied to nowadays diesel engines with a benefit of low pollution.

High environmental friendliness and sustainability and it contain neither sulfur, nor aroma. These facts lead biodiesel to enhance more complete combustion and less emission of particulate matter [26,27]. Recently, catalytic pyrolysis has aroused a great interest for the

*Corresponding author: Zeban Shah, Federal University of Rio, Grande do Sul, Av. Bento Goncalves, Porto Alegre, RS, Brazil, Tel: +555182634325; E-mail: zs_zaib77@yahoo.com

Received February 16, 2016; Accepted May 31, 2016; Published July 02, 2016

Citation: Shah Z, Veses RC, Silva R (2016) A Comparative Study and Analysis of Two Types of Bio-Oil Samples Obtained from Freshwater Algae and Microbial Treated Algae. Mod Chem appl 4: 185. doi:10.4172/2329-6798.1000185

Copyright: @ 2016 Shah Z, et al. This is an open-access article distributed under the terms of the Creative Commons Attribution License, which permits unrestricted use, distribution, and reproduction in any medium, provided the original author and source are credited. 
Citation: Shah Z, Veses RC, Silva R (2016) A Comparative Study and Analysis of Two Types of Bio-Oil Samples Obtained from Freshwater Algae and Microbial Treated Algae. Mod Chem appl 4: 185. doi:10.4172/2329-6798.1000185

Page 2 of 7

advantages of operating at atmospheric pressure and the lack of need for hydrogen $[28,29]$. Recently, increasing attention has been paid to the recovery of chemicals from bio-oil, providing chemicals compared to fuels could make recovery of even small concentrations viable. As we all know, most of oxygen-containing organic compounds, such as phenols, ketones and alcohols are value-added chemicals used in industry and life [30].

\section{Experimental}

\section{Preparation of FWA and other reagents}

The FWA was first converted to powder form then it was dried in fresh air and sunlight until 10\% moisture remained, the fine powder FWA was introduced into a plastic jar. The plastic jar was closed through lid in such a way that it became air tight. The jar was kept at room temperature for 3 days, then the sample was used as FWA biomass sample and finally this WFA biomass sample was introduced to pyrolysis in the presence of catalyst calcium oxide.

\section{Preparation of MTA and other reagents}

The FWA was first converted to powder form and then carried out in a cylindrical plastic jar provided with an air tight lid. Fine powder FWA was put into the plastic jar and one liter tap water was added to it and mixed well. Then plastic jar was closed trough lid in such a way that it became air tight. The jar was kept at room temperature and after 7 days rhizopus appeared on its surface, it was due to the addition of tap water which believed to contain microbes. Then everyday water was sprayed on its surface and mixed well, this process was also maintained for 7 days. Then the sample was dried and used as MTA biomass sample in the presence of same catalyst (Cao).

\section{Production of bio-oil (FWAB and MTAB) from FWA and MTA biomass through pyrolysis}

The bio-oil was produced from the pyrolysis of FWA and MTA. A round block shaped structure of sample was made inside the filter paper from biomass (filter paper as side wall of the sample block to kept the biomass tight) while the weight of this sample was kept 150 grams, also some amount of sand was added to the mixture for some purposes (as heat resistant). After preparation of this sample block, it was fixed inside the stainless steel reactor which was further connected to other condensation chambers which are shown in the diagram in Figures 1-6. The temperature of the reactor was increased from $25-650^{\circ} \mathrm{C}$ time by time, through which biomass was converted to biogas and then the biogas was condensed in condensation chamber as bio-oil (FWAB and MTAB). The condensed fractions from condensation chamber were collected and introduced to fractional distillation. The bio-oil obtained at the optimum conditions was separated into fractions by distillation. The bio-oil was separated into four fractions including residue. These fractions were found in the temperature range of 65$200^{\circ} \mathrm{C}$ and the residue of distillation. The first fraction was obtained in the temperature range of $65-100^{\circ} \mathrm{C}$, the second fraction was collected in the range $100-150^{\circ} \mathrm{C}$, the third fraction was found in the range of $150-180^{\circ} \mathrm{C}$, the fourth fraction was at $180-200^{\circ} \mathrm{C}$. The first fraction of FWAB and MTAB is flammable while the remaining all fractions are nonflammable. However the residue of the fractional distillation was a sticky organic material and believed as combustible.

\section{GC-MS characterization of the FWAB and MTAB after pyrolysis}

The GC-MS analysis Table 1 was carried out in order to find out the compounds present in both types of bio-oil samples. The main peaks identification of compounds has been performed by using NIST mass

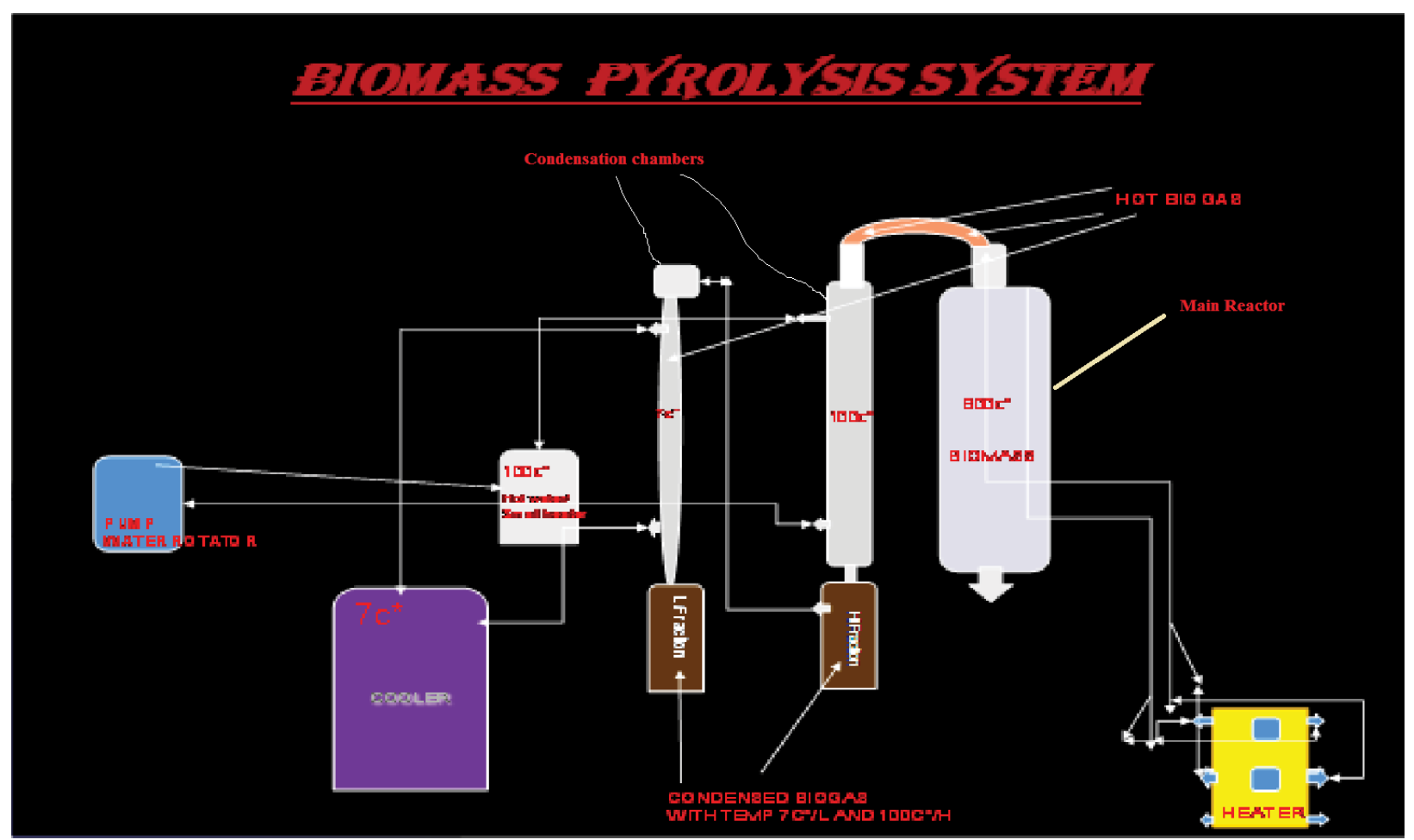

Figure 1: The biomass pyrolysis system. 
Citation: Shah Z, Veses RC, Silva R (2016) A Comparative Study and Analysis of Two Types of Bio-Oil Samples Obtained from Freshwater Algae and Microbial Treated Algae. Mod Chem appl 4: 185. doi:10.4172/2329-6798.1000185

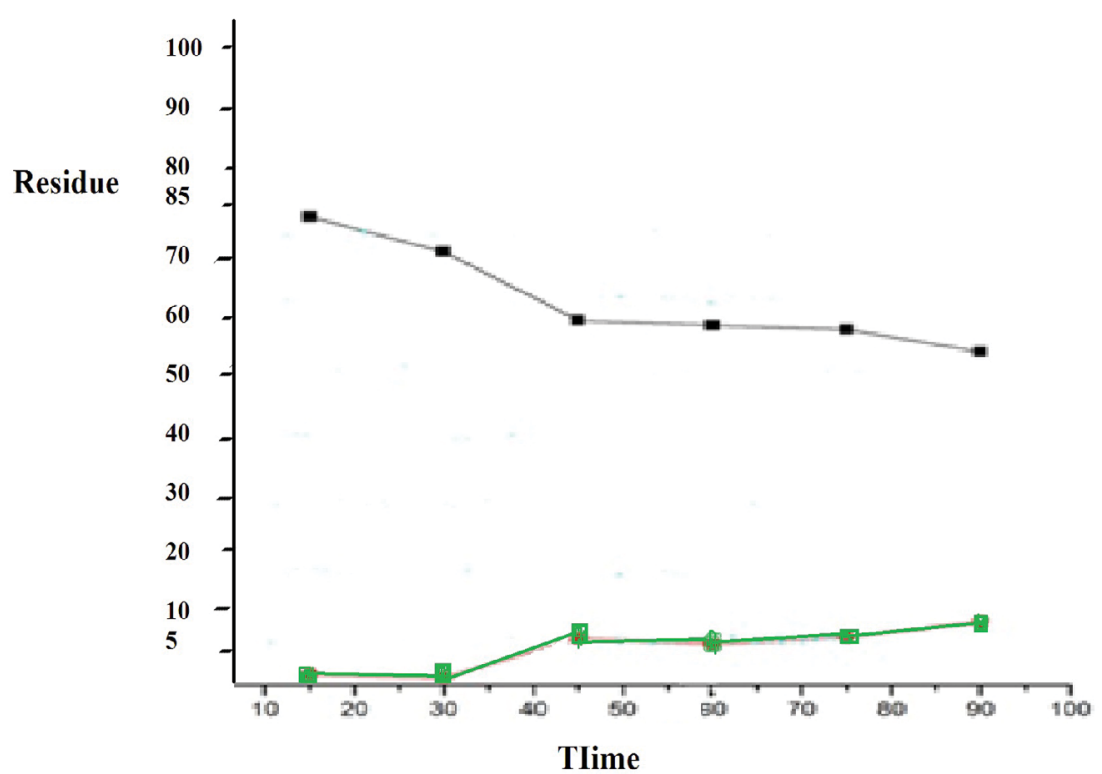

Figure 2: Shows the relationship between Residues and time during pyrolysis.

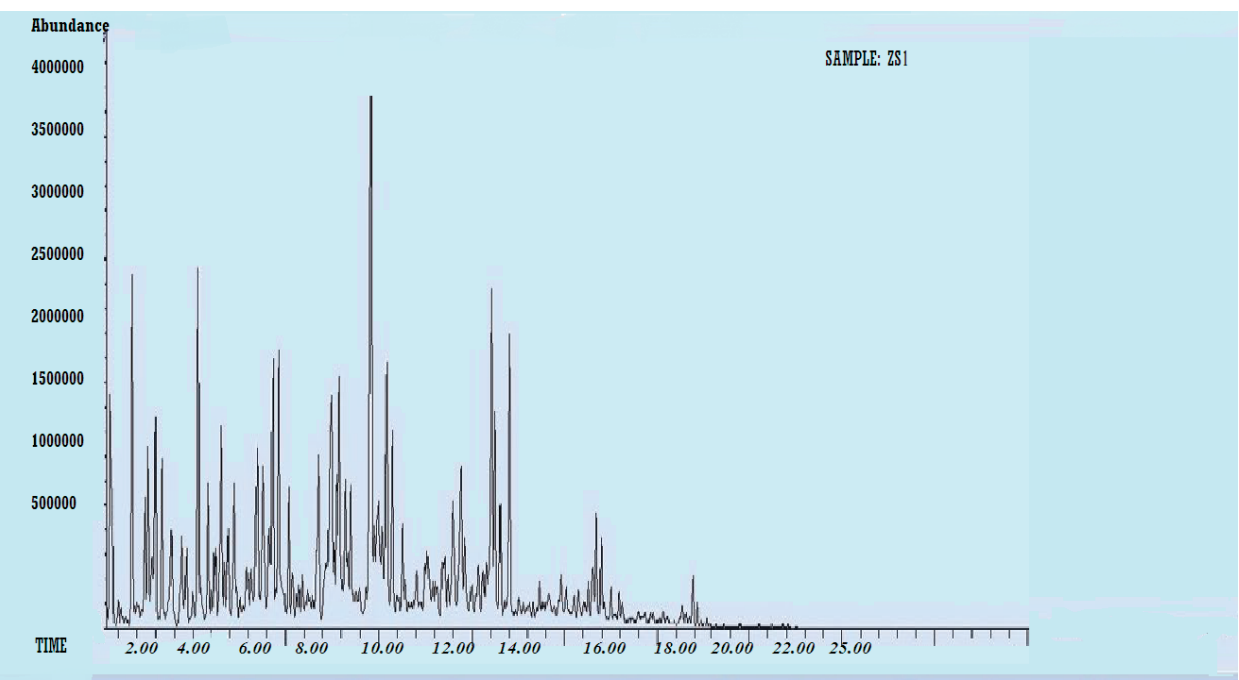

Figure 3: GC/MS Chromatogram of the FWAB.

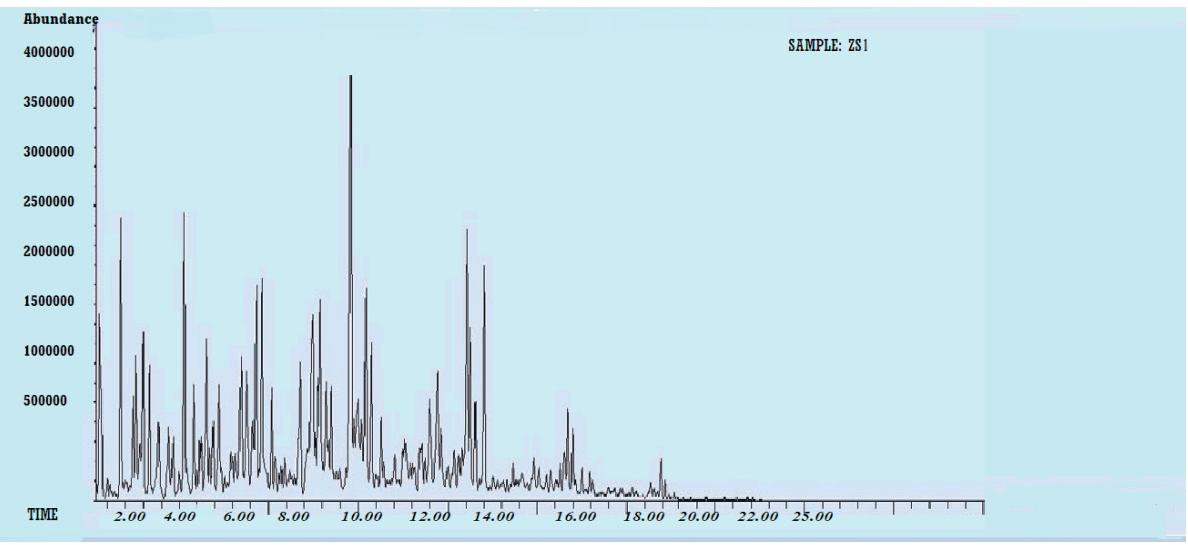

Figure 4: GC-MS Chromatogram of the MTAB 


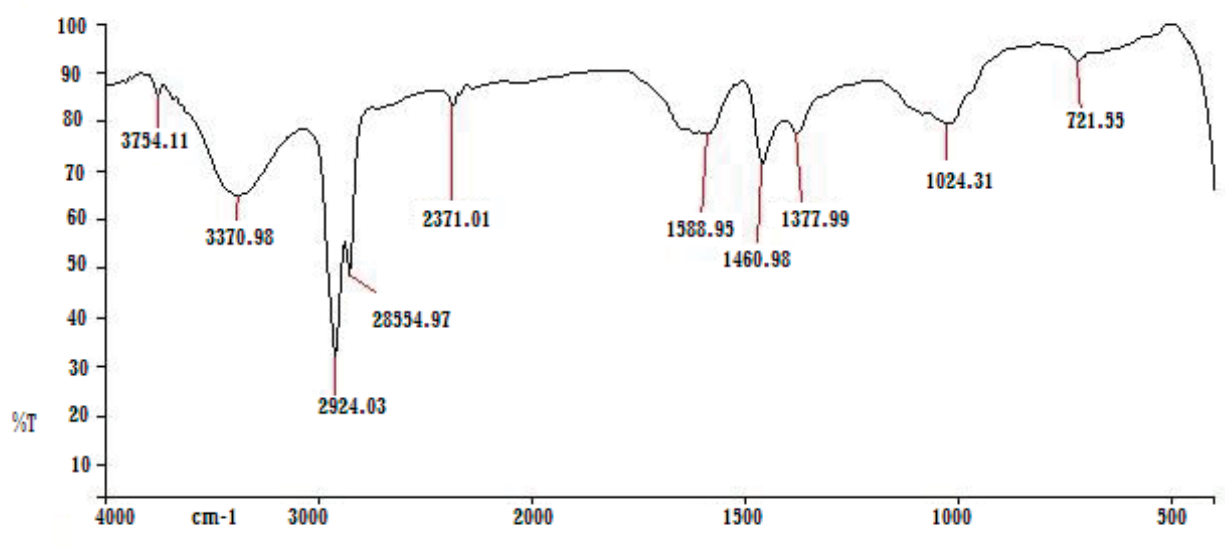

Figure 5: FTIR Spectrum of FWAB.

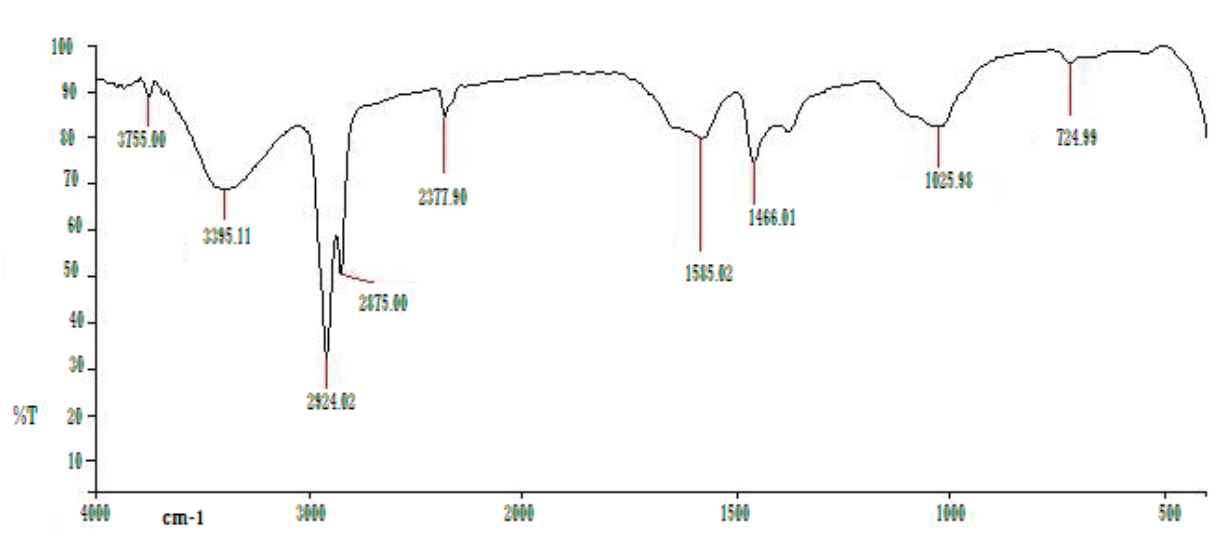

Figure 6: FTIR Spectrum of MTAB.

spectral data base. Both FWAB and MTAB were complex mixture and contain different classes of hydrocarbons and other compounds, which are shown in the Tables 2 and 3 respectively.

Table 2 is the FWAB's table which contains different compounds. The GC-MS results indicate the presence of different compounds which includes azole, aromatic amines and nitriles, carbohydrate, alkenes, alkanes and many others. The most abundant compound 2,3,5-trimethyl pyrazole $19.09 \%$ accounted for the total bio-oil. The azoles including 3,4,5-trimethyl-pyrazole, pyrrolidinone etc. and aromatic amine and nitrile, these compounds are assumed to be derived from protein degradation. While the 2,3, 4-trimethyl-d-xylose derived from the hydrolysis of cellulose. The alkenes class compound 3, 7,11, 15-tetramethyl-2-hexadecene is probably generated from the conversion of unsaturated fatty acid in algal cells. Long chain compound Pentadecane accounted $6.10 \%$ of the total oil, which contributes better combustion property of the algal fuel.

Table 3 is the MTAB's table in which different compounds are shown. The GC-MS analysis results indicate the presence of different classes of hydrocarbons and other compounds which includes azoles, azene, nitriles, and long chain aliphatic compounds and some others. The different $\%$ composition of every organic compound in the fuel is listed in the Table 3. The most abundant compound 2-pyrrolidinone accounted for $25.20 \%$ of the total oil. The azoles and azene which indicate the class of nitrogen containing heterocyclic compounds such as 3,4,5-Trimethyl pyrazole, 2-pyrolidinone, 1,2,4,5-Trimethyl-
$1 \mathrm{H}$-imidazole, belongs to azole class while the piperidinone belong to azene class. These compounds were supposed to be produce due to the degradation of protein in algal biomass. The tetradecanenitril and Hexadecaneperoxoic are long chain aliphatic compounds containing nitrile and ester functional group. The tetradecanenitrile and Hexadecaneperoxoic acid accounted $14.10 \%$ and $14.26 \%$ respectively of the total bio-oil, which contribute better combustion property of the algal fuel.

\section{Results and Discussion}

\section{Theoretical bases of the pyrolysis of biomass/Spirogyra}

Spirogyra is blue green algae which is a cellulosic biomass, and is considered as third generation bio-fuel. It is used for the preparation of liquid and gaseous fuels. It contains small quantity of the lignin. Its growth and multiplication is very rapid. The pyrolysis of the cellulosic biomass gives water soluble oxygenated compounds. It is thought that the cellulosic biomass may manufacture methanol, anhydrosugars, furans and aldehydes compounds. These compounds can be used as fuel if appropriately utilized. These products are formed along with large quantity of water therefore need treatment to use as fuel. The product of pyrolysis also contains oil like liquid which is believed that it is composed of compounds containing less oxygen contents. These are partially soluble in the aqueous mixture. Different pre-treatment procedures are used in this work to increase the oily products and to decrease the contents of organic acids as well as other reactive 
Citation: Shah Z, Veses RC, Silva R (2016) A Comparative Study and Analysis of Two Types of Bio-Oil Samples Obtained from Freshwater Algae and Microbial Treated Algae. Mod Chem appl 4: 185. doi:10.4172/2329-6798.1000185

Page 5 of 7

\begin{tabular}{|c|c|c|c|c|}
\hline S. No & Temperature $\left({ }^{\circ} \mathrm{C}\right)$ & Weight of biomass $(\mathrm{g})$ & \% Residue & \% Liquid \\
\hline 1 & 250 & 120 & 92.89 & 7.01 \\
\hline 2 & 350 & 120 & 0.103 & 20.11 \\
\hline 3 & 450 & 120 & 62.77 & 25.99 \\
\hline 4 & 550 & 120 & 57.10 & 26.97 \\
\hline 5 & 650 & 120 & 53.10 & 11.24 \\
\hline
\end{tabular}

Table 1: Important data of Temperature for Pyrolysis of FWA and MTA.

\begin{tabular}{|c|c|c|c|c|}
\hline S. No & Name of compounds & Compounds Formula & Retention Time & $\%$ composition \\
\hline 1 & 2,2-dimethylpropiophenone & $\mathrm{C}_{11} \mathrm{H}_{14} \mathrm{O}$ & 2.12 & 2.05 \\
\hline 2 & 3,4,5- tri-methyl pyrazole & $\mathrm{C}_{6} \mathrm{H}_{10} \mathrm{~N}_{2}$ & 2.97 & 19.09 \\
\hline 3 & 2-pyrrilidinone & $\mathrm{C}_{4} \mathrm{H}_{7} \mathrm{NO}$ & 2.41 & 8.05 \\
\hline 4 & 1-H-imidazole1,2,4,5-tetramethyl & $\mathrm{C}_{7} \mathrm{H}_{12} \mathrm{~N}$ & 3.43 & 14.25 \\
\hline 5 & 3-methylbutanenitrile & $\mathrm{C}_{5} \mathrm{H}_{9} \mathrm{~N}$ & 3.75 & 2.10 \\
\hline 6 & 2,3,4-trimethyl-d-xylose & $\mathrm{C}_{8} \mathrm{H}_{16} \mathrm{O}_{5}$ & 3.93 & 14.09 \\
\hline 7 & Benzonitrile, 4-methyl & $\mathrm{C}_{8} \mathrm{H}_{7} \mathrm{~N}$ & 4.35 & 5.16 \\
\hline 8 & Pyrrole & $\mathrm{C}_{4} \mathrm{H}_{5} \mathrm{~N}$ & 4.45 & 2.05 \\
\hline 9 & Pentadecane & $\mathrm{C}_{15} \mathrm{H}_{32}$ & 6.21 & 6.10 \\
\hline 10 & Benzenamine,N-(1-methyl-2-propyl) & $\mathrm{C}_{9} \mathrm{H}_{13} \mathrm{~N}$ & 6.35 & 5.23 \\
\hline 11 & Benzocyclobuten & $\mathrm{C}_{8} \mathrm{H}_{8}$ & 7.52 & 2.04 \\
\hline 12 & Phenol & $\mathrm{C}_{6} \mathrm{H}_{6} \mathrm{O}$ & 9.75 & 1.43 \\
\hline 13 & 2-hexadecene3,7,11,15-tetramethyl & $\mathrm{C}_{20} \mathrm{H}_{4} \mathrm{O}$ & 9.92 & 4.09 \\
\hline 14 & Hexadecanenitrile & $\mathrm{C}_{16} \mathrm{H}_{31} \mathrm{~N}$ & 10.59 & 9.02 \\
\hline 15 & 2-methoxy-3H-azepine & $\mathrm{C}_{7} \mathrm{H}_{9} \mathrm{NO}$ & 11.07 & 2.15 \\
\hline 16 & 1-chloro-3-fluorobenzene & $\mathrm{C}_{6} \mathrm{H}_{4} \mathrm{CIF}$ & 12.55 & 2.11 \\
\hline
\end{tabular}

Table 2: GC-MS shows the compounds present in FWAB after pyrolysis.

\begin{tabular}{|c|c|c|c|c|}
\hline S. No & Name of compounds & Compounds Formula & Retention Time & $\%$ Composition \\
\hline 1 & Isobutyronitrile & $\mathrm{C}_{4} \mathrm{H}_{7} \mathrm{~N}$ & 2.33 & 2.75 \\
\hline 2 & 2-pyrrilidinone & $\mathrm{C}_{4} \mathrm{H}_{7} \mathrm{No}$ & 2.424 & 25.20 \\
\hline 3 & 3,4,5-trimethyl pyrazole & $\mathrm{C}_{6} \mathrm{H}_{10} \mathrm{~N}_{2}$ & 2.939 & 9.25 \\
\hline 4 & 2-piperidinone & $\mathrm{C}_{5} \mathrm{H}_{9} \mathrm{~N}$ & 3.289 & 13.30 \\
\hline 5 & 1H-imidazole. 1,2,4,5-tetramethyl & $\mathrm{C}_{7} \mathrm{H}_{12} \mathrm{~N}$ & 3.420 & 14.16 \\
\hline 6 & Hexadecane-peroxoic acid & $\mathrm{C}_{16} \mathrm{H}_{32} \mathrm{O}_{3}$ & 3.557 & 14.26 \\
\hline 7 & 2-methylpyrazine & $\mathrm{C}_{5} \mathrm{H}_{6} \mathrm{~N}_{2}$ & 5.91 & 2.10 \\
\hline 8 & 1,4-pentadien-3-one & $\mathrm{C}_{5} \mathrm{H}_{6} \mathrm{O}$ & 6.45 & 2.50 \\
\hline 9 & 2,5-dimethylpyridine & $\mathrm{C}_{7} \mathrm{H}_{9} \mathrm{~N}$ & 8.38 & 1.40 \\
\hline 10 & Tetradecanenitrile & $\mathrm{C}_{14} \mathrm{H}_{27} \mathrm{~N}$ & 10.590 & 14.10 \\
\hline 11 & 1-methyl-3-vinyl-1H-pyrazole & $\mathrm{C}_{6} \mathrm{H}_{8} \mathrm{~N}_{2}$ & 11.93 & 1.22 \\
\hline
\end{tabular}

Table 3: GC-MS table of the compounds present in MTAB after pyrolysis.

compounds, as oxygenated and nitrogenated species, because they not only lead to high corrosiveness and acidity, but also set up many obstacles to applications.

\section{Infrared spectroscopy (IR) results of FWAB}

In Table 4, Results of FWAB indicate that $(\mathrm{C}-\mathrm{H})$ alkanes stretching at $2924.09 \mathrm{~cm}^{-1}$ and intense broad peak and axial at $3000 \mathrm{~cm}^{-1}$. While alkanes bending occurs at $1359.2 \mathrm{~cm}^{-1}$ and the peak intensity is variable. The $(\mathrm{O}-\mathrm{H})$ is also a weak broad peak is due to the presence of water content in bio-oil or may be due to alcohol which appears at 3456.44 $\mathrm{cm}^{-1}$. The strong intensity due to stretching vibration of ether appears at $1238.30 \mathrm{~cm}^{-1}$. The aromatic $\mathrm{C}=\mathrm{C}$ stretching at $1556.55 \mathrm{~cm}^{-1}$ its intensity is medium weak multiple band The alkene $=\mathrm{C}-\mathrm{H}$ stretching at 3080.32 $\mathrm{cm}^{-1}$ and its intensity is also medium while the alkenes stretching occur at $1645.28 \mathrm{~cm}^{-1}$ and the intensity of peak is variable. It is concluded that the presence of different functional group of compounds indicate the presence of hydrocarbons in the fuel and also the $(\mathrm{O}-\mathrm{H})$ broad peak indicate the presence of water contents in bio-fuel. The broad $\mathrm{O}-\mathrm{H}$ peak was due to the interaction (hydrogen bonding) among the water contents. This oil sample consists of Alkanes, Alkenes, ether, alcohols and aromatics.

\section{Infrared spectroscopy (IR) results of MTAB}

The IR results are shown in the Table 5. Indicates that there is 
Citation: Shah Z, Veses RC, Silva R (2016) A Comparative Study and Analysis of Two Types of Bio-Oil Samples Obtained from Freshwater Algae and Microbial Treated Algae. Mod Chem appl 4: 185. doi:10.4172/2329-6798.1000185

Page 6 of 7

\begin{tabular}{|c|c|c|c|}
\hline Functional group & Type of vibration & Characteristics Absorption $\mathbf{~ ( c m}^{-1}$ ) & Intensity \\
\hline C-O (Ether) & Stretch & 1238.30 & Strong \\
\hline- - - (Alkane) & Bending & 1359.82 & Variable \\
\hline C=C (Aromatic) & Stretch & 1556.55 & Medium-weak, multiple bands. \\
\hline C-H (Alkane) & Stretch & 2924.09 & Strong \\
\hline -C-H (Alkene) & Stretch & 3080.32 & Medium \\
\hline O-H (Alcohol) & Stretch (H-bonded) & 3456.44 & Strong, broad \\
\hline Alkene & Stretch & 1645.28 & Variable \\
\hline
\end{tabular}

Table 4: Characteristics IR Absorption frequencies of organic functional groups of FWAB.

\begin{tabular}{|c|c|c|c|}
\hline Functional group & Type of vibration & Characteristics Absorption (cm-1) \\
\hline C-O (Ether) & Stretch & 1242.16 \\
\hline -C-H (Alkane) & Bending & 1373.32 \\
\hline C=C (Aromatic) & Stretch & 1444.68 \\
\hline C=C (Alkene) & Stretch & 1643.35 \\
\hline C-H (Alkane) & Stretch & 2920.23 \\
\hline C-H (Alkene) & Stretch & 3088.03 \\
\hline O-H (Alcohol) & (stretched-bonded) & 3412.08 \\
\hline
\end{tabular}

Table 5: Characteristics IR Absorption frequencies of organic functional groups of MTAB.

a broad peak in the region of $3200 \mathrm{~cm}-1$ to $3600 \mathrm{~cm}^{-1}$ because this spectrum is the water soaked and microbial treated sample in which due to the hydrolysis of cellulose sugar is formed. The residue sample indicates that $(\mathrm{C}-\mathrm{H})$ alkanes stretching at $2920.23 \mathrm{~cm}^{-1}$ and intense broad peak and axial at $3000 \mathrm{~cm}^{-1}$. While alkanes bending occurs at $1373.32 \mathrm{~cm}^{-1}$ and the peak intensity is variable. The strong intensity due to stretching vibration of ether appears at $1242.16 \mathrm{~cm}^{-1}$. The aromatic $\mathrm{C}=\mathrm{C}$ stretching at $1444.68 \mathrm{~cm}^{-1}$ its intensity is medium weak multiple band. The alkenes stretching at $1643.35 \mathrm{~cm}^{-1}$ and the intensity of peak is variable. While the stretching of alkenes at $3088.03 \mathrm{~cm}^{-1}$ the intensity of peak is strong and broad. It was concluded that the different functional groups indicate the presence of different classes of hydrocarbons.

\section{Catalytic optimization}

Numerous reaction were carried out in which the amount of catalyst was remained the same while biomass was varying to choose a suitable ratio of catalyst with biomass at which maximum liquid oil while less amount of $\%$ residue is obtained. At different ratio of catalyst and biomass the pyrolysis reactions were carried out, finally 1:10 of catalyst and biomass respectively in both FWA and MTA, was found proper for good product yield of pyrolysis.

\section{Conclusions}

Pyrolysis of algal biomass was performed in a stainless steel reactor to investigate the effects of pyrolysis temperature, particle size and catalyst on product yields. As we have used two samples of Algae (FWA and MTA) in this study, that's why it is clear in results, tables and figures that there is a considerable difference between these two biooil samples. The microbial action converts the cellulosic biomass into compounds of low oxygen contents. Anyhow spirogyra as a biomass for bio-oil production was found very useful due to its unignorable effect on the products of pyrolysis. In addition to the pre-treatment the catalyst $(\mathrm{CaO})$ was found more efficient in increasing the amount of the bio-oil product in both cases (FWA and MTA). Pyrolysis of algal biomass is a promising process for both renewable fuel production and environment. Our future work will be extraction of important chemicals like Phenols from these bio-oil and also formulation (10\%$20 \%$ ) of these bio-oil with common diesel oil to use it in a diesel engine, the engine will shows us particulate matter (PM) emission, output power and efficiency of these bio-oil.

\section{Acknowledgements}

This research was supported by The Brazilian National Council for Scientific and Technological Development (CNPq.Brazil).

\section{References}

1. Yang HM (2015) Separation of phenols and ketones from bio-oil produced from ethanolysis of wheat stalk. Separ Purif Technol 152: 238-245.

2. Undri A (2015) A simple procedure for chromatographic analysis of bio-oils from pyrolysis. J Anal Appl Pyrol.

3. Huber GW, Iborra S, Corma A (2006) Synthesis of transportation fuels from biomass chemistry catalysts and engineering. Chem Rev 106: 4044-4098.

4. Zeng FX, Liu WJ, Jiang H, Yu HQ, Zeng RJ, et al. (2011) Separation of phthalate esters from bio-oil derived from rice husk by a basification-acidification process and column chromatography. Bioresour Technol 102: 1982-1987.

5. Dupont C, Chiriac R, Gauthier G, Toche F (2014) Heat capacity measurements of various biomass types and pyrolysis residues. Fuel 115: 644-651.

6. Pollard AS, Rover MR, Brown RC (2012) Characterization of bio-oil recovered as stage fractions with unique chemical and physical properties. J Anal Appl Pyrolysis 93: 129-138.

7. Amen-Chen C, Pakdel H, Roy C (1997) Separation of phenols from Eucalyptus wood tar. Biomass Bioenergy 13: 25-37.

8. Ashraful AM, Masjuki HH, Kalam MA, Rizwanul Fattah IM, Imtenan S, et al (2014) Production and comparison of fuel properties engine performance and emission characteristics of biodiesel from various non-edible vegetable oils a review. Energy Convers Manage 80: 202-228.

9. Hoekman SK, Broch A, Robbins C, Ceniceros E, Natarajan M, et al. (2012) Review of biodiesel composition.

10. Bagby (1987) Vegetable oils for diesel fuel opportunities for development ASAE 87: 1588.

11. Sivalakshmi S, Balusamy T (2013) Effect of biodiesel and its blends with diethy ether on the combustion, performance and emissions from a diesel engine. Fuel 106: 106-110. 
Citation: Shah Z, Veses RC, Silva R (2016) A Comparative Study and Analysis of Two Types of Bio-Oil Samples Obtained from Freshwater Algae and Microbial Treated Algae. Mod Chem appl 4: 185. doi:10.4172/2329-6798.1000185

Page 7 of 7

12. Shay EG (1993) Diesel fuel from vegetable oils status and opportunities Biomass Bioenergy 4: 227-242.

13. Özbay N, Uzun BB, Varol EA, Pütün AE (2006) Comparative analysis of pyrolysis oils and its subfractions under different atmospheric conditions. Fuel Processing Technology 87: 1013-1019.

14. Diasakou M, Louloudi A, Papayannakos N (1998) Kinetics of the non-catalytic transesterification of soybean oil. Fuel 77: 1297-1302.

15. Adams C, Peters JF, Rand MC, Schorer BJ, Ziemke MC (1983) Investigation of soybean oil as a Diesel fuel extender endurance test. JAOCS 60: 1574-1579.

16. Darnoko D, Cheryan M (2000) Kinetics of palm oil transesterification in a batch reactor. JAOCS 77: 1263-1267.

17. Isıgıgur A, Karaosmonoglu F, Aksoy HA (1994) Methyl ester from safflower seed oil of Turkish origin as a biofuel for Diesel engines. Appl Biochem Biotechnol 45: 103-112.

18. Freedman B, Pryde EH (1982) Fatty esters from vegetable oils for use as a Diesel fuel. In: Proceedings of the International Conference on Plant and Vegetable Oils as Fuels, pp: 17-122.

19. Fuls J, Hugo FJC (1981) On farm preparation of sunflower oil esters for fuel. In Third International Conference on Energy Use Management, pp: 1595-1602.

20. Laksmono N, Paraschiv M, Loubar K, Tazerout M (2013) Biodiesel production from biomass gasification tar via thermal/catalytic cracking. Fuel Processing Technology 106: 776-783.

21. Dukua MH, Gu S, Hagan EB (2011) A comprehensive review of biomass resources and biofuels potential in Ghana. Renewable and Sustainable Energy Reviews 15: 404-415.
22. AbouZaid MM, Nozzolillo C, Tonon A, Coppens M, Lombardo DA, et al. (2008) High-performance liquid chromatography characterization and identification of antioxidant polyphenols in maple syrup. Pharm. Biol $46: 117-125$

23. DeSaint JY, Laumer E, Cicchetti P, Merle J, Egger A, et al. (2010) Quantification in gas chromatography: prediction of flame ionization detector response factors from combustion enthalpies and molecular structures. Anal Chem. 82: 64576462

24. Wang H, Provan GJ, Helliwell K (2003) HPLC determination of catechins in tealeaves and tea extracts using relative response factors. Food Chem 81 : 307-312.

25. Bridgwater AV, Peacocke GVC (2000) Fast pyrolysis processes for biomass Renew Sustain Energy Rev 4: 1-73.

26. Bridgwater AV (2003) Renewable fuels and chemicals by thermal processing of biomass. Chem Eng J 91: 87-102.

27. Stas M, Kubicka D, Chudoba J, Pospísil M (2014) Overview of analytica methods used for chemical characterization of pyrolysis bio-oil. Energy Fuels 28: 385-402.

28. Yang HM (2015) Separation of phenols and ketones from bio-oil produced from ethanolysis of wheat stalk. Separ Purif Technol 152: 238-245.

29. Wang SR, Wang YR, Cai QJ, Wang XY, Jin H, et al. (2014) Multi-step separation of monophenols and pyrolytic lignins from the water-insoluble phase of bio oil. Sep Purif Technol. 122: 248-255.

30. Bridgwater AV, Meier D, Radlein D (1999) An overview of fast pyrolysis of biomass. Org Geochem. 30: 1479-1493. 